\title{
COOPERAÇÃO NO SETOR PÚBLICO: ESTUDOS BRASILEIROS QUE ABORDAM OS CONSÓRCIOS PÚBLICOS COMO UNIDADES DE ANÁLISE
}

\author{
SILVA, Jessica Natália da ${ }^{1}$ \\ TAVARES, Bruno ${ }^{2}$ \\ CASTRO, Sabrina Olímpio Caldas de ${ }^{3}$
}

\begin{abstract}
RESUMO: O objetivo do estudo consistiu em apresentar os estudos brasileiros que abordam os consórcios públicos como unidades de análise, destacando, principalmente, a metodologia utilizada pelos autores. Para tanto, foram realizadas buscas nas bases de dados Scientific Eletronic Library Online (SciELO) e Scientific Periodicals Electronic Library (SPELL) entre os anos 1992 e 2018, tomando por referência o resumo dos artigos. Os resultados indicaram que muitos estudos que tratam dos consórcios públicos utilizam da abordagem qualitativa, sendo mais explorado o estudo de caso. Quanto à coleta e análise de dados, foram identificados os usos de entrevistas e documentos e da Análise de Conteúdo como os mais frequentes. No entanto, muitos estudos não configuram o uso de documentos como pesquisas documentais e/ou mencionam de forma explícita as técnicas de análise utilizadas. O artigo contribui na medida em que pretende auxiliar pesquisadores e também induzir novas pesquisas, já que expõe algumas lacunas a serem exploradas. Além disso, a contribuição para com a literatura também foi destacada pelo mapeamento realizado, sendo possível ter um panorama geral dos estudos que tratam dos consórcios públicos.
\end{abstract}

Palavras-chave: Associativismo público. Federalismo. Aspectos metodológicos.

\section{COOPERATION IN THE PUBLIC SECTOR: BRAZILIAN STUDIES THAT ADDRESS PUBLIC CONSORTIUMS AS ANALYSIS' UNITS}

\begin{abstract}
SUMMARY: The aim of the study was to present the Brazilian studies that approached the indicators of behavior through an analysis, highlighting, mainly, a technique used by the authors. In order to do so, we searched the databases of the Electronic Scientific Electronic Library (SciELO) and the Scientific Library of Electronic Periodicals (SPELL) between 1992 and 2018, based on the summary of articles. The results indicated that many studies dealing with consortia used the qualitative approach and were further explored in the case study. As for the collection and analysis of data, the uses of interviews and documents and analysis of content were included as the most frequent ones. However, many studies do not configure the use of documents as documental searches and / or explicitly as analysis techniques used. The article in that it shows the initiatives of support and research, since it exposes some gaps to be explored. In addition, a contribution to the literature was also highlighted by the mapping carried out, and it is possible to have an overview of the studies that deal with public consortia.
\end{abstract}

Keywords: Public consorts. Federalism. Methodological aspects.

\section{INTRODUÇÃO}

As redes, enquanto novas formas organizacionais vêm ganhando cada vez mais espaço na literatura, bem como em ambientes institucionais. No âmbito público, em especial, tais estruturas são observadas enquanto relacionadas a algumas teorias e termos, como por exemplo: governança, redes de políticas públicas e associativismo (ABRUCIO; SANO; SYDOW, 2010; CKAGNAZAROFF;

\footnotetext{
${ }^{1}$ Professora da Faculdade Dinâmica do Vale do Piranga (FADIP).Doutoranda do Programa de Pós-Graduação em Administração da Universidade Federal de Viçosa

${ }^{2}$ Professor doutor do Departamento de Administração e Contabilidade da Universidade Federal de Viçosa

${ }^{3}$ Doutoranda do Programa de Pós-Graduação em Administração da Universidade Federal de Viçosa
} 
ABREU, 2009; DALLABRIDA, 2010; LISTONE; FILIPPIM, 2014; SANTOS, 2005; SCHNEIDER, 2005).

A ação cooperada no âmbito público passou a ter maior importância a partir da descentralização proposta pela Constituição de 1988. Com tal medida, os municípios, por exemplo, tornaram-se mais responsáveis por ações e formulações de políticas públicas. Dessa forma, mais autônomos (COLNAGO; HESPANHOL, 2014). Destaca-se, no entanto, que assumir tal responsabilidade para os tais entes não é simples, visto que os mesmos encontram desafios, como, por exemplo, condições financeiras, administrativas e políticas (ABRUCIO; SANO; SYDOW, 2010).

Como apontam alguns estudos (ABRUCIO; SANO e SYDOW, 2010; ABRUCIO; FILIPPIM; DIEGUEZ, 2013) a cooperação e a descentralização devem estar articuladas, partindo-se da premissa de que cada ente atuando de forma isolada, não poderia formular e implementar todas as suas ações. Dessa forma, a cooperação pode proporcionar a integração de políticas públicas, fazendo com que as vantagens ou os ganhos sejam compartilhados e, consequentemente, aconteçam numa perspectiva territorial ampliada.

Entendidos como uma forma de cooperação pública, os consórcios públicos podem ser caracterizados como instrumentos de gestão governamental que possibilitam interação de diferentes esferas de governo, com o propósito de articular iniciativas e políticas públicas (RAVANELLI, 2010). De acordo com Abrucio et al. (2010), existem alguns fatores que podem favorecer o consorciamento, entre eles: a identidade regional; as "tragédias comuns"; a constituição de lideranças políticas regionais; apoio e indução dos governos federais e estaduais; a existência de marcos legais que tornem a cooperação mais atrativa.

Não obstante, os autores anteriormente apresentados destacam também que os consórcios podem encontrar dificuldades para serem implementados e também para que continuem atendendo a sociedade, tais obstáculos estão relacionados a: comportamento individualista dos municípios; ausência de identidade regional; brigas político-partidárias; falta de indução federativa por parte de outros governos (estadual e federal); gestão pública frágil; conflitos intergovernamentais; o pouco destaque que o associativismo territorial ocupa na agenda pública brasileira.

Com relação à abordagem dos consórcios na literatura, verificou-se que existem muitos estudos que discutem a figura dos mesmos na resolução de problemas locais (MORAIS; CHAVES, 2016; FELICORI et al., 2016); que apresentam os consórcios como formas de entrega e implementação de serviços (FERRAES; CORNONI JÚNIOR, 2007; KRANKS; ROSA 2015); que expõem a história e a formulação de consórcios (ANGNES; MATOS, 2013; PITERMAN; REZENDE; HELLER, 2016); que apresentam os consórcios a partir das relações intergovernamentais e interorganizacionais (MATOS; DIAS, 2012; ROCHA, 2016); e, ainda, que indicam os consórcios como formas de governança local, abordando aspectos ligados à gestão (HENRICHS; MEZA, 2017; TEIXEIRA; DOWELL; BUGARIN, 2003). No entanto, não foram observadas pesquisas que fazem um panorama dos estudos sobre consórcios, principalmente observando os aspectos metodológicos.

Como intuito de contribuir com a literatura no que tange aos consórcios públicos, pretende-se então responder à seguinte questão de pesquisa: como os consórcios públicos têm sido abordados na literatura brasileira? O objetivo do estudo, portanto, consiste em apresentar os estudos brasileiros que abordam os consórcios públicos como unidades de análise, destacando, principalmente, a metodologia utilizada pelos autores.

Entende-se que a observação de estudos a partir do viés metodológico, além de refletir o que vem sendo estudado, aponta também lacunas teóricas quanto aos objetos de pesquisa e unidades de análise a serem exploradas. Além disso, diante dos estudos já realizados sobre os consórcios públicos, tem-se a 
premissa de que a maioria dos estudos que focam nestas entidades tem abordagens qualitativas e utilizam de entrevistas e documentos para ter acesso às formas de entrega e implementação de serviço, à história e a formulação de consórcios, para discutir os mesmos a partir das relações intergovernamentais e interorganizacionais e indicá-los como formas de governança local,

Além desta seção, este artigo está dividido em outras quatro seções. A próxima seção consiste na revisão de literatura. Posteriormente, são apresentados os procedimentos metodológicos, os resultados e as contribuições do estudo.

\section{REVISÃO DE LITERATURA}

\subsection{Federalismo e Descentralização do Estado}

Segundo Santos e Andrade (2012) a noção de Estado Federal é relativamente moderna no contexto da ciência política, não ultrapassando três séculos. No entanto, nos últimos dois séculos, o federalismo tem promovido repercussão nas constituições, principalmente quando se trata da repartição de competências entre os entes estatais. Neste sentido, de forma lenta e gradual, tem havido mudança no que tange aos poderes dos órgãos centrais e os órgãos periféricos.

De acordo com os autores mencionados anteriormente, quando se trata da definição de federalismo não se tem um consenso pleno. Para este estudo em específico, será utilizado o conceito de Affonso (2000), que afirma que o federalismo é caracterizado pela difusão dos poderes de vários centros, de tal forma que a autoridade não seja exercida por um único ente, mas sim, que a autoridade seja descentralizada e que haja autonomia por parte dos entes públicos.

Existem, de acordo com Santos e Andrade (2012), dois princípios básicos do federalismo, tais princípios compreendem: a) participação, no sentido que todos os entes são partes ativas no processo de elaboração da vontade pública; b) autonomia, que defende que todos os entes públicos têm liberdade para construir suas próprias ordens constitucionais, desde que tais ordens respeitem os princípios da Constituição Federal.

Além dos princípios apresentados anteriormente, Soares (1988) apresenta as principais características dos sistemas federais, a saber: a) divisão do poder central em várias subunidades; b) representação das subunidades federadas junto ao Governo Federal através do Senado; c) presença do legislativo, executivo e judiciário nas unidades federadas; d) existência de uma Corte Suprema de Justiça responsável pela resolução de conflitos federativos; e) definição de competências às esferas federativas (competências administrativas e fiscais); f) autonomia dos entes federativos para a construção dos próprios governos.

Para os autores citados anteriormente, a Constituição é a base da construção federativa, e neste sentido, é ela que delimita as esferas estatais, sem, contudo, perder a união e a harmonia. Cada Estadomembro, conforme o princípio federativo, tem sua parcela dos três poderes: legislativo, executivo e judiciário, assim como o Estado Federal, no entanto, àqueles possuem tais parcelas em proporção relativa ao seu território.

Para Abrucio et al. (2013), além da constituição de instituições básicas, o funcionamento de uma federação deve se dar a partir da dinâmica das relações intergovernamentais, que é validada pela forma como os atores federativos interagem e montam suas estratégias de atuação. Para tais autores, as relações intergovernamentais não dependem apenas de mecanismos formais, mas da interação entre os interesses dos mesmos, bem como suas identidades e recursos. 
De acordo com Abrucio, Sano e Sydow (2010), as relações interorganizacionais, principalmente no âmbito público, podem levar a um dilema: a busca pela garantia da autonomia em detrimento da necessidade de lidar com as desigualdades regionais. Neste sentido, os autores afirmam que as formas de associativismo territorial, como é o caso dos consórcios públicos, podem induzir à cooperação.

\subsection{Os municípios e os consórcios públicos nas constituições republicanas}

Antes da promulgação da Constituição Federal de 1891 os municípios eram considerados meros instrumentos de interesse dos coronéis. Após a promulgação da primeira constituição republicana, também pouco se atentava para a figura destes entes federativos, apenas o artigo 68 apresentava que "Os Estados organizar-se-ão de forma que fique assegurada a autonomia dos Municípios em tudo quanto respeite ao seu peculiar interesse" (BRASIL, 1891).

Apesar disso, a autonomia não se concretizou, os municípios ficaram ainda sob responsabilidade dos coronéis e do Estado, podendo este último intervir na competência dos primeiros.

Com relação aos consórcios, os mesmos ainda não eram assim denominados na Constituição de 1891, eles eram vistos como contratos e deveriam obter aprovação do Governo do Estado, caso os membros de tais consórcios fossem municípios e aprovação da União, caso fossem constituídos por estados.

A Constituição de 1937 previu algumas responsabilidades e atribuições aos municípios, dentre elas: a escolha dos Vereadores pelo sufrágio direto dos munícipes alistados eleitores na forma da lei; a decretação dos impostos e taxas atribuídos à sua competência por esta Constituição e pelas Constituições e leis dos Estados (imposto de licença, imposto predial e territorial urbano, imposto sobre diversões públicas, taxas sobre serviços municipais); a organização dos serviços públicos de caráter local (BRASIL, 1937). Apesar isso, a escolha dos prefeitos, por exemplo, era de livre nomeação do governador do Estado.

Com relação aos consórcios, a Constituição Federal de 1937 apresentou que em seu artigo 29, que "os Municípios da mesma região podem agrupar-se para a instalação, exploração e administração de serviços públicos comuns. O agrupamento, assim constituído, será dotado de personalidade jurídica limitada a seus finns" (BRASIL, 1937). Porém, pouco se avançou com relação à regulação de consórcios públicos, propriamente.

Na Constituição de 1946, em seu artigo 28, a autonomia dos municípios ficou assegurada a partir dos seguintes elementos: eleição do Prefeito e dos Vereadores; pela administração própria, no que concerne ao seu peculiar interesse e, especialmente: a) à decretação e arrecadação dos tributos de sua competência e à aplicação das suas rendas; b) à organização dos serviços públicos locais. Além disso, a União também passou a transferir parte de alguns impostos arrecadados para os municípios (10\%), como por exemplo, aquele sobre consumo de mercadorias.

Ressalta-se, no entanto, que nem todos os municípios poderiam eleger seus prefeitos, pois conforme apresentam os parágrafos $\S 1$ e $\S 2$ do artigo 28:

$\S 1^{\text {o }}$ Poderão ser nomeados pelos governadores dos Territórios os prefeitos das respectivas capitais, bem como pelos governadores dos Estados e Territórios os prefeitos dos Municípios onde houver estâncias hidrominerais naturais, quando beneficiadas pelo Estado ou pela União.

$\S 2^{\circ}$ - Serão nomeados pelos Governadores dos Estados ou dos Territórios os Prefeitos dos Municípios que a lei federal, mediante parecer do Conselho de Segurança Nacional, declarar bases ou portos militares de excepcional importância para a defesa externa do País (BRASIL, 1946) 
Com relação aos consórcios, a Constituição de 1946 teve por intuito apresentar a ideia da autonomia federativa e deu maior importância aos consórcios públicos. No entanto, conforme apresentado por Prates (2012) tal autonomia acabou restringida pelo Regime Militar, que ocorreu dezenove anos depois.

A Constituição de 1967 previu a autonomia dos municípios através do artigo 16, ficando assegurado que: a eleição dos prefeitos, vice-prefeitos e vereadores seria realizada em todo o país, dois anos antes de se eleger o governador, os deputados e senadores; os municípios seriam responsáveis por sua administração própria, principalmente: a partir da decretação e arrecadação dos tributos de sua competência e à aplicação de suas rendas, sem prejuízo da obrigatoriedade, de prestar contas e publicar balancetes nos prazos fixados em lei estadual; da organização dos serviços públicos locais. Apesar disso, assim como na Constituição Federal de 1946, alguns municípios teriam seus prefeitos nomeados pelo governador, como é o caso dos Prefeitos das Capitais dos Estados e dos Municípios considerados estâncias hidrominerais em lei estadual e dos Prefeitos dos Municípios declarados de interesse da segurança nacional, por lei de iniciativa do Poder Executivo (BRASIL, 1967).

No que se refere aos consórcios, a Constituição de 1967, que foi promulgada no período militar, acabou por conceber os consórcios públicos apenas como pactos de colaboração.

Foi somente em 1988 que a Constituição Federal reconheceu os municípios como entes federativos. Já no artigo $1^{\circ}$ da referida constituição "A República Federativa do Brasil, formada pela união indissolúvel dos Estados e Municípios e do Distrito Federal" (BRASIL, 1988). Antes disso, nas constituições anteriores, o Brasil era formado pela união dos Estados, do Distrito federal e dos Territórios. Além disso, os artigos 29, 30, 31 e 156 apresentam a ampliação da autonomia dos municípios diante das constituições federais anteriores. A partir da CF88 os municípios são responsáveis, por exemplo, por elaborar suas próprias leis orgânicas.

O artigo 241 da Constituição Federal de 1988 apresenta também, pela primeira vez a nomenclatura "consórcios públicos":

Art. 241. A União, os Estados, o Distrito Federal e os Municípios disciplinarão por meio de lei os consórcios públicos e os convênios de cooperação entre os entes federados, autorizando a gestão associada de serviços públicos, bem como a transferência total ou parcial de encargos, serviços, pessoal e bens essenciais à continuidade dos serviços transferidos (BRASIL, 1988)

Ainda com relação à Constituição Federal de 1988, o Artigo 37 define que os consórcios, não importando a área de atuação, estão sujeitos a alguns princípios, sejam eles: a) legalidade; b) impessoalidade; c) moralidade; d) publicidade; e) eficiência.

Os aspectos discutidos anteriormente são sintetizados no Quadro 1: 
Quadro 1: Implicações para os municípios e para os consórcios públicos nas constituições republicanas

\begin{tabular}{|c|c|c|}
\hline Constituição & Implicações para os municípios & $\begin{array}{l}\text { Implicações para os } \\
\text { consórcios públicos }\end{array}$ \\
\hline $\begin{array}{l}\text { Constituição } \\
\text { Federal de } \\
1891\end{array}$ & Os coronéis e o Estado ditavam a autonomia municipal & $\begin{array}{l}\text { Os consórcios públicos são } \\
\text { constituídos como contratos }\end{array}$ \\
\hline $\begin{array}{l}\text { Constituição } \\
\text { Federal de } \\
1937\end{array}$ & $\begin{array}{l}\text { Algumas responsabilidades e atribuições dos municípios } \\
\text { começam a ser demarcadas, entre elas: a escolha de } \\
\text { vereadores; a decretação dos impostos e taxas (imposto } \\
\text { de licença, imposto predial e territorial urbano, imposto } \\
\text { sobre diversões públicas, taxas sobre serviços } \\
\text { municipais); a organização dos serviços públicos de } \\
\text { caráter local. Apesar isso, a escolha dos prefeitos, por } \\
\text { exemplo, era de livre nomeação do governador do } \\
\text { Estado }\end{array}$ & $\begin{array}{l}\text { Previu que os municípios da } \\
\text { mesma região podem } \\
\text { agrupar-se para a instalação, } \\
\text { exploração e administração } \\
\text { de serviços públicos comuns. } \\
\text { O agrupamento, assim } \\
\text { constituído, será dotado de } \\
\text { personalidade jurídica } \\
\text { limitada a seus fins }\end{array}$ \\
\hline $\begin{array}{l}\text { Constituição } \\
\text { Federal de } \\
1946\end{array}$ & $\begin{array}{l}\text { Alguns municípios poderiam eleger seus prefeitos e } \\
\text { vereadores (exceto onde houver estâncias hidrominerais } \\
\text { naturais, quando beneficiadas pelo Estado ou pela } \\
\text { União; quando declarar bases ou portos militares de } \\
\text { excepcional importância para a defesa externa do País); } \\
\text { decretação e arrecadação dos tributos de sua } \\
\text { competência e à aplicação das suas rendas; organização } \\
\text { dos serviços públicos locais. Além disso, a Unão } \\
\text { também passou a transferir parte de alguns impostos } \\
\text { arrecadados para os municípios (10\%), como por } \\
\text { exemplo, aquele sobre consumo de mercadorias }\end{array}$ & $\begin{array}{l}\text { Procurou resgatar a ideia de } \\
\text { autonomia federativa. No } \\
\text { entanto, tal autonomia acabou } \\
\text { restringida pelo Regime } \\
\text { Militar, que ocorreu } \\
\text { dezenove anos depois }\end{array}$ \\
\hline $\begin{array}{l}\text { Constituição } \\
\text { Federal de } \\
1967\end{array}$ & $\begin{array}{l}\text { Previu a autonomia dos municípios ficando assegurado } \\
\text { que: a eleição dos prefeitos, vice-prefeitos e vereadores } \\
\text { seria realizada em todo o país, dois anos antes de se } \\
\text { eleger o governador, os deputados e senadores; os } \\
\text { municípios seriam responsáveis por sua administração } \\
\text { própria, principalmente: a partir da decretação e } \\
\text { arrecadação dos tributos de sua competência e à } \\
\text { aplicação de suas rendas, sem prejuízo da } \\
\text { obrigatoriedade, de prestar contas e publicar balancetes } \\
\text { nos prazos fixados em lei estadual; da organização dos } \\
\text { serviços públicos locais. Apesar disso, assim como na } \\
\text { Constituição Federal de 1946, alguns municípios teriam } \\
\text { seus prefeitos nomeados pelo governador }\end{array}$ & $\begin{array}{l}\text { Os consórcios públicos foram } \\
\text { colocados como meros pactos } \\
\text { de colaboração }\end{array}$ \\
\hline $\begin{array}{l}\text { Constituição } \\
\text { Federal de } \\
1988\end{array}$ & $\begin{array}{l}\text { reconheceu os municípios como entes federativos. Os } \\
\text { artigos } 29,30,31 \text { e } 156 \text { apresentam a ampliação da } \\
\text { autonomia dos municípios diante das constituições } \\
\text { federais anteriores. A partir da CF } 88 \text { os municípios são } \\
\text { responsáveis, por exemplo, por elaborar suas próprias } \\
\text { leis orgânicas. }\end{array}$ & $\begin{array}{l}\text { Os municípios e o Distrito } \\
\text { Federal são reconhecidos } \\
\text { como entes federativos e a } \\
\text { ideia do consorciamento } \\
\text { ganha força }\end{array}$ \\
\hline
\end{tabular}

Fonte: Elaborado pelo Autor

Mesmo após a promulgação da Constituição de 1988 os consórcios públicos ainda eram pouco mencionados na lei, visto que o Artigo 241 não dispunha de informações completas que evidenciassem a posição jurídica dos mesmos (RIBEIRO, 2007). Assim sendo, por falta de estatuto jurídico adequado, estados e municípios não conseguiam exercer um papel colaborativo com outros entes públicos.

Em 1995, no entanto, com a aprovação da Proposta de Emenda Constitucional no 19/1988, a redação do Artigo 241 foi alterada e dessa forma, os consórcios públicos obtiveram as seguintes mudanças: a) foram disciplinados por lei; b) se tornaram pessoas jurídicas; c) poderiam ser formados por 
entes federativos de níveis distintos; d) poderiam autorizar a gestão associada de serviços públicos (RIBEIRO, 2007; BORGES, 2005).

Ribeiro (2007) ressalta que a mudança ocorrida na Constituição Federal (Artigo 241) não foi suficiente, pois os efeitos práticos da Emenda Constitucional dependiam de mudanças na legislação federal. Dez anos depois, em 6 de abril de 2005 foi criada então a Lei de Consórcios Públicos n ${ }^{\circ} 11.107$. A regulamentação de tal lei, o Decreto 6.017, de 17/01/2007 foi realizada dois anos após a sua criação.

\section{METODOLOGIA}

Quanto à natureza, a pesquisa se classifica como qualitativa. De acordo com Gray (2012), a pesquisa qualitativa, entre outros fatores, tem uma posição epistemológica mais construtivista, existe uma relação mais próxima entre o sujeito e o objeto a ser pesquisado e possui caráter mais indutivo.

A coleta de dados foi realizada a partir de uma revisão de literatura visando buscar artigos que tivessem como tema os consórcios públicos. Para tanto, foram realizadas buscas nas bases de dados Scientific Eletronic Library Online (SciELO) e Scientific Periodicals Electronic Library (SPELL) entre os anos 1992 e 2018, a partir dos resumos dos artigos. Os dados foram coletados em outubro de 2018 com base nas seguintes palavras-chave: "consórcio"/“consórcios" (com e sem acento), "consórcio intermunicipal", "cooperação intergovernamental", "interestadual" e "intermunicipal". A partir destas buscas, foram encontrados 572 artigos na base SciELO e 115 artigos na base SPELL. Cabe ressaltar que tanto na base SciELO quanto na base SPELL a busca se deu a partir dos resumos dos artigos.

Após as buscas, foram feitas as leituras dos resumos dos artigos, com o objetivo de verificar se os artigos realmente se referiam aos consórcios no âmbito público, sendo então excluídos os consórcios privados e público-privados. Além disso, foi verificado ainda se os artigos selecionados compreendiam análises de consórcios ou somente os citavam enquanto parte de outra análise. Caso isso ocorresse, tais artigos seriam excluídos. Assim, após a leitura dos resumos, foram selecionados quarenta e dois artigos para comporem a base de dados deste estudo, conforme apresentado no Quadro 2.

Quadro 2: Artigos encontrados nas bases SciELO e SPELL que analisam os consórcios públicos

\begin{tabular}{|c|c|c|c|}
\hline Artigo & Título & Base & Ano \\
\hline A1 & $\begin{array}{c}\text { Gestão Ambiental: Desafios e Possibilidades de Novos Arranjos } \\
\text { Institucionais }\end{array}$ & SPELL & 1992 \\
\hline A2 & $\begin{array}{c}\text { Associativismo como instrumento de desenvolvimento dos governos } \\
\text { locais: a experiência brasileira e de outros países }\end{array}$ & SPELL & 1997 \\
\hline A3 & $\begin{array}{c}\text { Consórcios Intermunicipais de Saúde no Estado de São Paulo: Situação } \\
\text { Atual }\end{array}$ & SciELO & 1999 \\
\hline A4 & Os Consórcios Intermunicipais de Saúde e o Sistema Único de Saúde & SciELO & 2000 \\
\hline A5 & Os Consórcios Intermunicipais de Saúde no Estado do Rio de Janeiro & SciELO & 2001 \\
\hline A6 & $\begin{array}{c}\text { Consórcios Intermunicipais de Saúde: Uma Análise à Luz da Teoria dos } \\
\text { Jogos }\end{array}$ & SciELO & 2003 \\
\hline A7 & $\begin{array}{c}\text { Federalismo e relações intergovernamentais: os consórcios públicos como } \\
\text { instrumento de cooperação federativa }\end{array}$ & SPELL & 2004 \\
\hline A8 & Consórcios Intermunicipais de Saúde: o caso do Paraná, Brasil & SciELO & 2005 \\
\hline A9 & Consórcio de medicamentos no Paraná: análise de cobertura e custos & $\begin{array}{c}\text { SciELO e } \\
\text { SPELL }\end{array}$ & 2006 \\
\hline A10 & Consórcios de saúde: estudo de caso exitoso & SciELO & 2006 \\
\hline A11 & $\begin{array}{c}\text { Avaliação da satisfação dos usuários com os serviços do consórcio } \\
\text { intermunicipal de saúde do noroeste do Paraná }\end{array}$ & SciELO & 2007 \\
\hline
\end{tabular}


Quadro 2: Artigos encontrados nas bases SciELO e SPELL que analisam os consórcios públicos

(continua)

\begin{tabular}{|c|c|c|c|}
\hline A12 & $\begin{array}{l}\text { A experiência vivida pelo ser-gestor no desenvolvimento regional em um } \\
\text { consórcio de pequenos municípios }\end{array}$ & SPELL & 2008 \\
\hline A13 & $\begin{array}{l}\text { A promoção do desenvolvimento local apoiada em redes de municípios: a } \\
\text { experiência do Consórcio Intermunicipal Central Paulista }\end{array}$ & SciELO & 2008 \\
\hline A14 & $\begin{array}{l}\text { Consórcios intermunicipais para a destinação de RSU em aterros regionais: } \\
\text { estudo prospectivo para os municípios no Estado do Paraná }\end{array}$ & SciELO & 2009 \\
\hline A15 & $\begin{array}{l}\text { Consórcio intermunicipal para a aquisição de medicamentos: impacto no } \\
\text { desabastecimento e no custo }\end{array}$ & SciELO & 2010 \\
\hline A16 & Cooperação intermunicipal na bacia do rio Paraopeba & $\mathrm{LO}$ & 2012 \\
\hline A17 & $\begin{array}{r}\text { O BSC e a Administração dos Consór } \\
\text { de Caso Sobre }\end{array}$ & ELL & 2012 \\
\hline A18 & Ações de Aprendizagem e Liderança em Consórcios da Área de Saúde & SPELL & 2012 \\
\hline A19 & $\begin{array}{l}\text { Inovação na cooperação intermunicipal no } \\
\text { Catarinense de Municípios (Fecam) na ce }\end{array}$ & $\begin{array}{c}\text { SciELO } \\
\mathrm{e} \\
\text { SPELL }\end{array}$ & 2013 \\
\hline A 20 & $\begin{array}{l}\text { Consórcio Intermunicipal da Fronteira } \\
\text { voltadas ao desenvolvimento regional } \\
\text { mun }\end{array}$ & $\begin{array}{l}\text { SciELO } \\
\mathrm{e} \\
\text { SPELL }\end{array}$ & 2013 \\
\hline A 21 & $\begin{array}{r}\text { Análise do Plano de Desenvolviment } \\
\text { Consórcio Sul-S }\end{array}$ & SciELO & 2013 \\
\hline A22 & $\begin{array}{r}\text { Relações Intergovernamentai } \\
\text { Públicos e Arranjc }\end{array}$ & SciELO & 2013 \\
\hline A 23 & Desenvolvimento regional: uma aná & $\begin{array}{c}\text { SciELO } \\
\text { e } \\
\text { SPELL }\end{array}$ & 2013 \\
\hline A 24 & $\begin{array}{r}\text { Ações Coletivas na Área da Saúde: } \\
\text { Intermunicipal de Saúde Costa Oeste } \\
\text { Serviços C }\end{array}$ & SPELL & 2014 \\
\hline A 25 & $\begin{array}{l}\text { Gestão interfederativa do } S \\
\text { Intermunicipal do }\end{array}$ & $\begin{array}{c}\text { SciELO } \\
\mathrm{e} \\
\text { SPELL }\end{array}$ & 2014 \\
\hline A26 & $\begin{array}{r}\text { A promoção da cooperação nos consórci } \\
\text { Par }\end{array}$ & SciELO & 2014 \\
\hline A 27 & $\begin{array}{l}\text { Análise sociométrica da rede de relacion } \\
\text { Consórcio das Universidades Feder }\end{array}$ & SciELO & 2014 \\
\hline A28 & $\begin{array}{l}\text { Cooperação intergovernamental, consórcios públicos e sistemas de distribuição } \\
\text { de custos e benefícios }\end{array}$ & $\begin{array}{c}\text { SciELO } \\
\mathrm{e} \\
\text { SPELL }\end{array}$ & 2014 \\
\hline A29 & $\begin{array}{r}\text { Desenvolvime } \\
\text { uma Est }\end{array}$ & LL & 2014 \\
\hline A 30 & $\begin{array}{r}\text { Percepçã } \\
\text { con }\end{array}$ & SciELO & 2015 \\
\hline A 31 & $\begin{array}{l}\text { Consórcio Intermunicipal do Vale do Rio Caí (Cis/Caí): Serviços Prestados de } \\
\text { Média e Alta Complexidade em Saúde }\end{array}$ & PELL & 2015 \\
\hline A 32 & $\begin{array}{c}\text { Relações de Cooperação em Consórcios Públicos de Regiões Metropolitanas: } \\
\text { análises do CONDIAM/PB e Consórcio Grande Recife/PE }\end{array}$ & iLL & 2015 \\
\hline A33 & $\begin{array}{l}\text { Identificação de áreas adequadas para a construção de aterros sanitários e usinas } \\
\text { de triagem e compostagem na mesorregião da Zona da Mata, Minas Gerais }\end{array}$ & LO & 2016 \\
\hline A34 & Distribuição espacial dos polos regionais do Cederj: uma & SciELO & 2016 \\
\hline A35 & $\begin{array}{r}\text { Capital social como conceito-chave para a avaliação do su } \\
\text { intermunicipais: o caso do CISMAE, Par }\end{array}$ & $\mathrm{O}$ & 20 \\
\hline
\end{tabular}


Quadro 2: Artigos encontrados nas bases SciELO e SPELL que analisam os consórcios públicos

(conclusão)

\begin{tabular}{|c|c|c|c|}
\hline A36 & $\begin{array}{c}\text { A cooperação federativa e a política de saúde: o caso dos Consórcios } \\
\text { Intermunicipais de Saúde no estado do Paraná }\end{array}$ & SciELO & 2016 \\
\hline A37 & $\begin{array}{c}\text { Perfil da Gestão de Consórcios Intermunicipais de Saúde do Rio Grande do Sul: } \\
\text { um Estudo das Práticas de Gestão Econômica e Financeira }\end{array}$ & SPELL & 2016 \\
\hline A38 & $\begin{array}{c}\text { Governança multinível para o desenvolvimento regional: um estudo de caso do } \\
\text { Consórcio Intermunicipal da Fronteira }\end{array}$ & SciELO & 2017 \\
\hline A39 & $\begin{array}{c}\text { Gestão Municipal Consorciada: a experiência do Consórcio de Informática na } \\
\text { Gestão Pública Municipal (CIGA) }\end{array}$ & $\begin{array}{c}\text { SciELO } \\
\text { e } \\
\text { SPELL }\end{array}$ & 2017 \\
\hline A40 & $\begin{array}{c}\text { Instrumentos de Ação Pública no Vale do Ribeira Casos do Consad e do Codivar } \\
\text { e } \\
\text { SPELL }\end{array}$ & $\begin{array}{c}\text { SciELO } \\
2018\end{array}$ \\
\hline A41 & $\begin{array}{c}\text { Cooperação Intergovernamental na política de mobilidade urbana: o caso do } \\
\text { Consórcio Intermunicipal do ABC }\end{array}$ & SciELO & 2018 \\
\hline A42 & $\begin{array}{c}\text { Políticas públicas em educação superior a distância }- \text { um estudo sobre a } \\
\text { experiência do Consórcio Cederj }\end{array}$ & SciELO & 2018 \\
\hline
\end{tabular}

Fonte: Dados da Pesquisa.

A análise dos dados se deu por meio da pesquisa bibliográfica. De acordo com o que apresenta Stumpf (2005), a pesquisa bibliográfica consiste na identificação, seleção, localização e obtenção de documentos de interesse para a realização de trabalhos acadêmicos. Tais documentos são, no entanto, de domínio científico, tais como: livros, periódicos, artigos e ensaios (SÁ-SILVA; ALMEIDA; GUINDANI, 2009).

\section{RESULTADOS}

Em uma primeira análise dos dados e remetendo-os ao que foi apresentado na discussão de literatura deste estudo, é possível afirmar que os estudos que tem por objetivo analisar os consórcios públicos no Brasil são recentes. Até os anos 2000, por exemplo, apenas três estudos foram realizados. Uma das possíveis justificativas para tanto é que os consórcios passaram se legitimar a partir da Constituição de 1988, data em que os municípios foram reconhecidos como entes federativos e a ideia de consorciamento e associação passou a ganhar força no cenário nacional (RIBEIRO, 2007; PRATES, 2012).

Ademais, a maioria dos artigos que se referem a consórcios públicos estão ligados aos consórcios intermunicipais, podendo ser associado mais uma vez à nova ideia do desenho federativo brasileiro, da autonomia municipal gerada (COLNAGO; HESPANHOL, 2014).

Quanto à metodologia em si, o Quadro 3 sintetiza as informações referentes à natureza dos artigos, o tipo/método de pesquisa empregado e os instrumentos de coleta e análise dos dados. 
Quadro 3: Artigos encontrados nas bases SciELO e SPELL que analisam os consórcios públicos

(continua)

\begin{tabular}{|c|c|c|c|c|}
\hline Artigo & Natureza & $\begin{array}{l}\text { Tipo/Método de } \\
\text { Pesquisa }\end{array}$ & Coleta de dados & $\begin{array}{l}\text { Análise dos } \\
\text { dados }\end{array}$ \\
\hline $\mathrm{A} 1$ & Qualitativo* & - & - & - \\
\hline A2 & Qualitativo* & - & - & - \\
\hline A3 & Qualitativo & Descritivo & Entrevista e Questionário & Não especificado \\
\hline A4 & $\begin{array}{l}\text { Qualitativo e } \\
\text { Quantitativo }\end{array}$ & $\begin{array}{l}\text { Descritivo e } \\
\text { Pesquisa } \\
\text { Bibliográfica }\end{array}$ & $\begin{array}{l}\text { Fontes secundárias e outros } \\
\text { estudos já realizados }\end{array}$ & Não especificado \\
\hline A5 & Qualitativo & $\begin{array}{c}\text { Descritivo e } \\
\text { Pesquisa } \\
\text { Bibliográfica }\end{array}$ & $\begin{array}{l}\text { Fontes secundárias e outros } \\
\text { estudos já realizados }\end{array}$ & Não especificado \\
\hline A6 & Quantitativo & Exploratório & $\begin{array}{c}\text { Foram construídos modelos para } \\
\text { a análise dos componentes da } \\
\text { Teoria dos Jogos nos CIS }\end{array}$ & Não especificado \\
\hline A7 & Qualitativo* & - & - & - \\
\hline A8 & $\begin{array}{l}\text { Qualitativo - } \\
\text { Quantitativo }\end{array}$ & Estudo de Caso & $\begin{array}{l}\text { Questionário, documentos } \\
\text { (relatórios) e fontes secundárias }\end{array}$ & Não especificado \\
\hline A9 & $\begin{array}{c}\text { Qualitativo - } \\
\text { Quantitativo ** }\end{array}$ & - & $\begin{array}{l}\text { Fontes secundárias e outros } \\
\text { estudos já realizados }\end{array}$ & $\begin{array}{l}\text { Descrição dos } \\
\text { dados coletados }\end{array}$ \\
\hline A10 & Qualitativo & Estudo de Caso & $\begin{array}{l}\text { Entrevistas, documentos e outros } \\
\text { estudos já realizados }\end{array}$ & Não especificado \\
\hline A11 & Quantitativo & Estudo transversal & Questionários & $\begin{array}{l}\text { Descrição dos } \\
\text { dados coletados }\end{array}$ \\
\hline A12 & Qualitativo & Hermenêutico & Entrevista & Análise temática \\
\hline A13 & Qualitativo*** & $\begin{array}{c}\text { Pesquisa } \\
\text { Biliográfica } \\
\end{array}$ & Estudos já realizados & - \\
\hline A14 & $\begin{array}{c}\text { Qualitativo - } \\
\text { Quantitativo ** }\end{array}$ & - & Fontes secundárias & - \\
\hline A15 & Qualitativo & $\begin{array}{c}\text { Pesquisa } \\
\text { Documental }\end{array}$ & Documentos do CIS estudado & Não especificado \\
\hline A16 & $\begin{array}{c}\text { Qualitativo - } \\
\text { Quantitativo ** }\end{array}$ & - & Fontes secundárias & - \\
\hline A17 & Qualitativo & Estudo de Caso & $\begin{array}{l}\text { Documentos, entrevistas e } \\
\text { observação participante }\end{array}$ & $\begin{array}{l}\text { Construção da } \\
\text { explanação }\end{array}$ \\
\hline A18 & Qualitativo & Estudo de Caso & $\begin{array}{c}\text { Questionários e análise } \\
\text { documental }\end{array}$ & $\begin{array}{l}\text { Análise de } \\
\text { Conteúdo }\end{array}$ \\
\hline A19 & Qualitativo & Estudo de Caso & $\begin{array}{c}\text { Estudo de casos correla- } \\
\text { tos, documentos, entrevistas e } \\
\text { observação direta }\end{array}$ & Não especificado \\
\hline A20 & Qualitativo & Estudo de Caso & $\begin{array}{l}\text { Documentos, estudos já } \\
\text { realizados e entrevistas }\end{array}$ & $\begin{array}{l}\text { Análise descritiva } \\
\text { e dos discursos }\end{array}$ \\
\hline A 21 & Qualitativo & $\begin{array}{c}\text { Pesquisa } \\
\text { documental }\end{array}$ & Documentos & $\begin{array}{l}\text { Análise de } \\
\text { Conteúdo }\end{array}$ \\
\hline A22 & Qualitativo* & - & - & - \\
\hline A23 & Qualitativo & Estudo de Caso & $\begin{array}{l}\text { Documentos, outros estudos já } \\
\text { realizados e entrevistas }\end{array}$ & $\begin{array}{l}\text { Análise de } \\
\text { Conteúdo }\end{array}$ \\
\hline A24 & Qualitativo & Estudo de Caso & $\begin{array}{c}\text { Dados secundários, obtidos de } \\
\text { sites } \\
\text { oficiais }\end{array}$ & $\begin{array}{l}\text { Descrição dos } \\
\text { dados coletados }\end{array}$ \\
\hline A25 & Qualitativo & $\begin{array}{l}\text { Pesquisa } \\
\text { Documental }\end{array}$ & Documentos & $\begin{array}{l}\text { Análise de } \\
\text { Conteúdo }\end{array}$ \\
\hline A26 & $\begin{array}{c}\text { Qualitativo - } \\
\text { Quantitativo ** }\end{array}$ & - & Questionários & Não especificado \\
\hline
\end{tabular}


Quadro 3: Artigos encontrados nas bases SciELO e SPELL que analisam os consórcios públicos

(conclusão)

\begin{tabular}{|c|c|c|c|c|}
\hline A27 & $\begin{array}{l}\text { Qualitativo - } \\
\text { Quantitativo }\end{array}$ & Estudo de Caso & Questionários & $\begin{array}{c}\text { Análise } \\
\text { sociométrica }\end{array}$ \\
\hline A28 & Qualitativo & Estudo de Caso & Dados secundários & Não especificado \\
\hline A29 & Qualitativo & Estudo de Caso & Documentos e entrevistas & $\begin{array}{l}\text { Análise de } \\
\text { conteúdo }\end{array}$ \\
\hline A30 & Qualitativo & Não especificado & Entrevistas & $\begin{array}{l}\text { Análise do } \\
\text { Discurso }\end{array}$ \\
\hline A31 & Quantitativo & $\begin{array}{l}\text { Estudo } \\
\text { transversal } \\
\text { retrospectivo }\end{array}$ & Dados secundários & $\begin{array}{c}\text { Descrição dos } \\
\text { dados coletados }\end{array}$ \\
\hline A32 & Qualitativo & Estudo de Caso & Documentos e entrevistas & $\begin{array}{l}\text { Análise de } \\
\text { Conteúdo }\end{array}$ \\
\hline A33 & $\begin{array}{l}\text { Qualitativo- } \\
\text { Quantitativo }\end{array}$ & Não especificado & Dados secundários & $\begin{array}{c}\text { Análise } \\
\text { multicritério }\end{array}$ \\
\hline A34 & Quantitativo & Não especificado & $\begin{array}{l}\text { Dados secundários e dados } \\
\text { coletados no Google Maps }\end{array}$ & Não especificado \\
\hline A35 & Qualitativo & Estudo de Caso & Entrevistas & $\begin{array}{l}\text { Análise de } \\
\text { Conteúdo }\end{array}$ \\
\hline A36 & Qualitativo & Estudo de Caso & Entrevistas & Não especificado \\
\hline A37 & $\begin{array}{l}\text { Qualitativo - } \\
\text { Quantitativo }\end{array}$ & - & Questionários & $\begin{array}{c}\text { Medição do } \\
\text { Ranking Médio } \\
\text { (RM), frequência } \\
\text { em percentual, } \\
\text { desvio padrão e } \\
\text { correlação. }\end{array}$ \\
\hline A38 & Qualitativo & Estudo de Caso & $\begin{array}{c}\text { Documentos, estudos já realizados } \\
\text { e entrevistas }\end{array}$ & $\begin{array}{l}\text { Análise de } \\
\text { Conteúdo }\end{array}$ \\
\hline A39 & Qualitativo & Estudo de Caso & Documentos e entrevistas & Não especificado \\
\hline A40 & Qualitativo & Estudo de Caso & $\begin{array}{l}\text { Documentos, entrevistas e } \\
\text { observação participante }\end{array}$ & Não especificado \\
\hline A41 & Qualitativo & Estudo de Caso & Documentos e entrevistas & Não especificado \\
\hline A42 & Qualitativo & Estudo de Caso & Documentos & Não especificado \\
\hline
\end{tabular}

Fonte: dados da pesquisa

*Artigo não continha metodologia, consistia em uma discussão teórica.

** Não especificado, a informação foi apresentada a partir da interpretação dos autores

*** Artigo não continha metodologia, mas descrevia a região estudada a partir de outros estudos já realizados.

Os resultados deste estudo, sintetizados a partir do Quadro 3, permitem corroborar com a premissa apresentada na introdução, ou seja, a maioria dos estudos têm os consórcios públicos como unidades de análise possuem abordagens mais qualitativas que quantitativas e utilizam documentos e entrevistas como fonte de dados. Uma observação a ser destacada, no entanto, é a de que mesmo os estudos analisados que utilizaram documentos, por muitas vezes, não apresentam que a pesquisa pode ser caracterizada também como uma pesquisa documental. Na maioria deles, citam apenas que se tratam de estudos de caso.

Um outro elemento importante consiste na observação da análise de dados. Muitos estudos não especificam como os dados foram tratados e analisados. Conforme apresentam Paiva Júnior et al., (2011), no entanto, uma pesquisa possui validade quando os métodos utilizados propiciam o alcance dos objetivos inicialmente propostos pelo pesquisador e também quando os autores expõem alguns critérios de qualidade das pesquisas, sendo eles: triangulação; reflexividade; construção do corpus da pesquisa; descrição clara, rica e detalhada; surpresa; feedback dos informantes. 
O intuito da observação acima não consiste em criticar os estudos analisados, mas de salientar sobre os aspectos essenciais de uma pesquisa científica, pois, ainda que, realizando a leitura dos artigos analisados, fosse possível inferir o tipo de análise, como, por exemplo, a análise de conteúdo, entende-se que os aspectos poderiam estar mais claros para a melhor compreensão do leitor. Voltando ao exemplo da análise de conteúdo, foi possível fazer inferências a partir do que foi proposto por Laville e Dione (1999), ou seja, de que essa técnica não possui um roteiro ou cronograma a ser seguido, mas sim um conjunto de vias possíveis para se chegar em um determinado conteúdo.

Ainda com relação aos achados, é possível destacar a ainda incipiente utilização da pesquisa quantitativa para a análise dos consórcios públicos. Por outro lado, existem mais artigos que utilizam os métodos mistos (qualitativos-quantitativos) do que estudos puramente quantitativos. Isso pode ser relevante para a compreensão do objeto e das unidades de análise, já que conforme expõem alguns autores (GRAY, 2012; PAIVA JÚNIOR; LEÃO; MELLO, 2011; VIEIRA, 2005) ambas as abordagens de pesquisa se complementam e devem ser utilizadas simultaneamente em um mesmo estudo.

$\mathrm{O}$ uso dos estudos de caso também chama atenção. Conforme exposto no quadro 2, a maioria dos estudos analisados trabalham com casos específicos no que concerne aos consórcios públicos. Um aspecto interessante desse método consiste no aprofundamento para a realização da pesquisa, e, ainda, maior aproximação entre o pesquisador e o objeto. No entanto, não é possível realizar comparações e fazer deduções a partir dos achados (YIN, 2015).

\section{CONSIDERAÇÕES FINAIS}

Por meio deste artigo foi possível apresentar os estudos brasileiros que abordam os consórcios públicos como unidades de análise, destacando, principalmente, a metodologia utilizada pelos autores.

Os resultados indicaram que muitos estudos que tratam dos consórcios públicos utilizam da abordagem qualitativa, sendo mais explorados os estudos de caso. Quanto à coleta de dados, o estudo identificou o uso de entrevistas e documentos como os mais frequentes, no entanto, muitos estudos não mencionam que o uso de documentos configura as pesquisas como documentais. Por fim, quanto à análise dos dados, apesar da análise de conteúdo ter sido destacada, muitos estudos sequer mencionam as técnicas de análise empregadas.

$\mathrm{O}$ artigo contribui em face da literatura existente, por auxiliar pesquisadores e também induzir novas pesquisas, pois expõe algumas lacunas a serem exploradas no âmbito dos consórcios públicos, como é o do uso de outros métodos nas pesquisas qualitativas e até mesmo o uso das pesquisas quantitativas no geral. Além disso, a contribuição para com a literatura também é válida pelo mapeamento realizado, sendo possível ter um panorama geral dos estudos que tratam dos consórcios públicos.

Como sugestão para estudos futuros, pode-se analisar novas bases de artigos, para além daquelas já aqui utilizadas. Além disso, pode-se realizar a pesquisa no âmbito internacional, explorando a figura dos consórcios e das cooperações intergovernamentais e também comparando os resultados aqui obtidos com essas pesquisas.

\section{REFERENCIAS}

ABRUCIO, F. L; FILIPPIM, E. S; DIEGUEZ, R. C. Inovação na cooperação intermunicipal no Brasil: a experiência da Federação Catarinense de Municípios (Fecam) na construção de consórcios públicos.

Revista de Administração Pública, v. 47, n. 6, p. 1543-1568, 2013. 
ABRUCIO, F. L; SANO, H; SYDOW, C. Radiografia do associativismo territorial brasileiro: tendências, desafios e impactos sobre as regiões metropolitanas. Regiões metropolitanas no Brasil. Washington: BID, p. 197-234, 2010.

AFFONSO, R. B. Á. Descentralização e reforma do Estado: a Federação brasileira na encruzilhada. Economia e Sociedade, v. 14, p. 127-152, 2000.

ANGNES, S. J; MATTOS, M. M. S. Consórcio Intermunicipal da Fronteira (CIF): descrevendo as principais ações voltadas ao desenvolvimento regional a partir da perspectiva do poder público municipal. Revista de Administração Pública, v. 47, n. 5, 1165-1188, 2013.

BORGES, A. G. Os consórcios públicos na sua legislação reguladora. Interesse Público, v. 7, p. 227-248, 2005.

BRASIL. Constituição da República Federativa do Brasil: promulgada em 5 de outubro de 1988.

BRASIL. Constituição (1891). Constituição da República dos Estados Unidos do Brasil. Rio de Janeiro, 1891. Disponível em http://www.planalto.gov.br/ccivil 03/constituicao/constituicao91.htm. Acesso em 17 mai. 2017.

BRASIL. Constituição (1937). Constituição da República dos Estados Unidos do Brasil. Rio de Janeiro, 1937. Disponível em http://www.planalto.gov.br/ccivil_03/constituicao/constituicao37.htm. Acesso em 17 mai. 2017.

BRASIL. Constituição (1946). Constituição dos Estados Unidos do Brasil. Rio de Janeiro, 1946. Disponível em http://www.planalto.gov.br/ccivil 03/constituicao/constituicao46.htm. Acesso:17/5/17.

BRASIL. Constituição (1967). Constituição da República Federativa do Brasil. Brasília, 1967. Disponível em http://www.planalto.gov.br/ccivil_03/constituicao/constituicao67.htm. Acesso:17/5/17.

BRASIL. Constituição (1988). Constituição da República Federativa do Brasil. Brasília, 1988. Disponível em http://www.planalto.gov.br/ccivil_03/constituicao/constituicao.htm. Acesso em 17 mai. 2017.

CASSIANO, K. M.et al. Distribuição espacial dos polos regionais do Cederj: uma análise estatística. Ensaio: Avaliação e Políticas Públicas em Educação, v. 24, n. 90, p. 82-108, 2016.

CKAGNAZAROFF, I. B; ABREU, B. V. A governança em planejamento e desenvolvimento local: uma análise teórica. Anais: Encontros Nacionais da ANPUR, v. 13, 2013.

COLNAGO, P; HESPANHOL, E. T. M. Políticas Públicas e Desenvolvimento Territorial: O Programa de Aquisição de Alimentos no Município de Dracena-SP. Geografia em Atos (Online), v. 2, n. 14, 2014.

DALLABRIDA, V. R. Desenvolvimento e governança territorial: um ensaio preliminar sobre a necessidade da regulação no processo de gestão do desenvolvimento. Redes, v. 15, n. 3, p. 165-186, 2010.

FELICORI, T. C.et al. Identificação de áreas adequadas para a construção de aterros sanitários e usinas de triagem e compostagem na mesorregião da Zona da Mata, Minas Gerais. Eng Sanit Ambient, 21(3), $547-560,2016$

FERRAES, A. M. B.,CORDONI JUNIOR, L. Consórcio de medicamentos no Paraná: análise de cobertura e custos. Revista de Administração Pública, 41(3), 475-486, 2007

GRAY, D. E. Pesquisa no mundo real. 2.ed. Porto Alegre: Penso, 2012. p.163-177.

HENRICHS, J. A; MEZA, M. L. F. G. Governança multinível para o desenvolvimento regional: um estudo de caso do Consórcio Intermunicipal da Fronteira. Revista Brasileira de Gestão Urbana, v. 9, n. 1, p. 124-138, 2017. 
KRANZ, L. F.; ROSA, R. S. Consórcio Intermunicipal do Vale Do Rio Caí (Cis/Caí): serviços prestados de média e alta complexidade em saúde. Gestão e Sociedade, v. 9, n. 23, 946-960, 2015

LISTONE, A. L. B.; FILIPPIM, E. S. Desafios para o associativismo de base territorial: o caso do projeto Tranças da Terra. DRd-Desenvolvimento Regional em debate, v. 4, n. 2, p. 78-102, 2014.

MATOS, F.; DIAS, R. Cooperação intermunicipal na bacia do rio Paraopeba. Revista de Administração Pública, v. 46, n. 5, 1225-1250, 2012.

MORAIS, V. S.; CHAVES, A. P. L. Percepção dos gestores municipais de saúde relacionada à saúde ambiental: consórcio intermunicipal de saúde Cerrado Tocantins Araguaia. Saúde e Sociedade, v. 25, p. 349-360, 2016.

PAIVA JÚNIOR, F. G.; LEÃO, A. L. M. S.; MELLO, S. C. B. Validade e Confiabilidade na Pesquisa Qualitativa em Administração. Revista de Ciências da Administração, v. 13, n. 31, p. 190-209, 2011.

PITERMAN, A.; REZENDE, S. C.; HELLER, L. Capital social como conceito-chave para a avaliação do sucesso de consórcios intermunicipais: o caso do CISMAE, Paraná. Engenharia Sanitaria e Ambiental, v. 21, n. $4,825-834,2016$.

PRATES, A. M. Q. Os consórcios públicos municipais no Brasil e a experiência europeia: alguns apontamentos para o desenvolvimento local. In: Congresso Consad de Gestão Pública, III, 2012.

RAVANELLI, P. Consórcios públicos: os desafios do fortalecimento de mecanismos de cooperação e colaboração entre os entes federados. In: Congresso Consad De Gestão Pública, III, Brasília, 2010.

RIBEIRO, W. A. Cooperação Federativa e a Lei de Consórcios Públicos. - Brasília DF: CNM, 2007.

ROCHA, C. V. A cooperação federativa e a política de saúde: o caso dos Consórcios Intermunicipais de Saúde no estado do Paraná. Cadernos Metrópole, v. 18, n. 36, p. 377-399, 2016.

SÁ-SILVA, J. R.; ALMEIDA, C. D.; GUINDANI, J. F. Pesquisa documental: pistas teóricas e metodológicas. Revista Brasileira de História \& Ciências Sociais, 1,1, jul. 2009. p.1-15.

SANTOS, H. Perspectivas contemporâneas para a constituição de redes de políticas públicas. CivitasRevista de Ciências Sociais, v. 5, n. 1, p. 59-68, 2005.

SANTOS, R. A.; ANDRADE, P. L. A evolução histórica do federalismo brasileiro: uma análise históricosociológica a partir das constituições federais. XXI Encontro Nacional do CONPEDI. Florianópolis: Fundação Boiteux, 2012.

SCHNEIDER, V. Redes de políticas públicas e a condução de sociedades complexas. Civitas-Revista de Ciências Sociais, v. 5, n. 1, p. 29-58, 2005.

STUMPF, I. R. C. Pesquisa bibliográfica. In: DUARTE, J.; BARROS, A. Métodos e Técnicas de Pesquisa em Comunicação. São Paulo: Atlas, v. 2, p. 51-61, 2005.

SOARES, M. M. Federação, democracia e instituições políticas. Lua Nova, v. 44, p. 137-163, 1998.

TEIXEIRA, L; DOWELL, M. C. M; BUGARIN, M. Consórcios intermunicipais de saúde: uma análise à luz da teoria dos jogos. Revista Brasileira de Economia, v. 57, n. 1, p. 253-281, 2003.

VIEIRA, M. M. F; ZOUAIN, D. M. Pesquisa qualitativa em administração. Rio de Janeiro: FGV. 237 p. Cap.1, 2005.

YIN, R. K. Estudo de caso: planejamento e métodos. 5. ed. Porto Alegre: Bookman, 2015 